\title{
Genetic evaluation and selection correlated response of growth traits in Japanese quail
}

\author{
M.M. El-Attrouny ${ }^{1 \#, ~ E . A . ~ M a n a a ~}{ }^{2}$ \& S.I. Ramadan ${ }^{2}$ \\ ${ }^{1}$ Department of Animal Productions, Faculty of Agriculture at Moshtohor, Benha University, Egypt \\ ${ }^{2}$ Animal and Poultry Production, Department of Animal Wealth Development, Faculty of Veterinary Medicine, Benha \\ University, Moshtohor, Toukh 13736, Qalyubia, Egypt
}

(Received 6 December 2019; Accepted 13 April 2020; First published online 18 May 2020)

Copyright resides with the authors in terms of the Creative Commons Attribution 4.0 South African License.
See: http://creativecommons.org/licenses/by/4.0/za
Condition of use: The user may copy, distribute, transmit and adapt the work, but must recognize the authors and the South African
Journal of Animal Science.

\begin{abstract}
Objectives of the current study were to i) investigate effects of selection for bodyweight at four weeks old on bodyweight (BW) and bodyweight gain (BWG) across four generations; ii) estimate correlated response to selection for BW and BWG at different ages; and iii) document best linear unbiased prediction (BLUP) of genetic trends for BW and BWG across four generations of selection. A total of 3540 chicks from 444 sires and 885 dams were used to estimate heritabilities, and genetic and phenotypic correlations for growth traits, including BW at 0,2, 4, and 6 weeks, and BWG between 0 and 2, 2 and 4, 4 and 6 , and 0 and 6 weeks. The selection effects, correlated responses and genetic trend for BW and BWG across generations were quantified by applying the animal model. Estimates of heritability for BW and BWG ranged from 0.22 to 0.42 and from 0.18 to 0.23 , respectively. Ranges of genetic and phenotypic correlations for BW varied from 0.31 to 0.92 and 0.05 to 0.65 , respectively. Moreover, estimates of genetic and phenotypic correlations for BWG at different ages were from 0.12 to 0.72 and 0.17 to 0.60 , respectively. Bodyweight and BWG estimates after four generations of selection were significantly higher than those of the base generation. Moreover, contrasts of generation means were significant across the four generations. The genetic trends across the generations clarified that BLUP estimates for BW and BWG gradually increased with the advance of generations until the fourth generation.
\end{abstract}

Keywords: best linear unbiased prediction, bodyweight, heritability, selection, genetic trend

"Corresponding author: Mahmoud.elatrouny@fagr.bu.edu.eg

\section{Introduction}

Japanese quail constitute one of the most productive poultry species. They play an important role in the commercial poultry industry because of their high egg and meat production (Mizutani, 2003; Boni et al., 2010). Moreover, they have many breeding advantages such as short generation interval, small floor space, high reproductive performance, early sexual maturity, rapid growth rate and high resistance to diseases (Baumgartner, 1994; Minvielle, 2004; Alkan et al., 2010). All these characteristics made Japanese quail an excellent model for selection programmes. The poultry industry aims mainly to produce genetically superior animals with high productivity of egg and meat. Studies on selection programmes as the most important tool for achieving genetic gain in quail have been performed in two directions: the first was to improve egg production traits (Nestor et al., 1983; Minvielle et al., 2000; Durmus et al., 2017); and the second to improve growth traits (Caron et al., 1990; Marks, 1993; Balcıoğlu et al., 2005; Ayatollahi Mehrgardi, 2013). In the second direction, weight gain was regarded as the most important selection criterion.

Selection for BW at four weeks in Japanese quail in long-term selection studies showed a positive correlation with BW in later weeks, genetic gain, age at sexual maturity and egg weight, and a negative correlation with reproductive traits and egg production rate (Marks, 1996; Khaldari et al., 2010). Moreover, the phenotypic mass selection approach in long-term selection studies was followed by an increase in BW at four weeks old (Darden \& Marks, 1988; Toelle et al., 1991; Resende et al., 2005; Varkoohi \& Kaviani, 2014). This illustrates the quick response to selection for higher BW in Japanese quail.

Genetic evaluations of economic traits such as BW and BWG at different ages are of great interest in most poultry breeding programmes (Silva et al., 2013). Therefore, most of the selection programmes have 
been based on estimates of genetic parameters for growth traits (Nasiri Foomani et al., 2014; Karami et al., 2017). Several studies indicated that selection based on genetic parameters of growth traits resulted in good selection responses in BW of Japanese quail (Nestor et al., 2000; Saatci et al., 2006). In selection studies, several methodologies were used to estimate the selection response. One of these methods was regression analysis for the estimates of the breeding values on generations. This approach depends on the genetic parameters and the model. To the authors' knowledge, most selection studies overlooked the differences between genetic perspectives, such as selection-correlated responses, genetic trends and BLUP estimates.

The authors hypothesized that selection methods that depend on BLUP estimates and genetic trend will reveal promising improvement in growth performance of Japanese quail. Therefore, the main objectives of the current study were to investigate the selection effects, selection correlated responses, genetic trends and BLUP estimates for BW and BWG in Japanese quail through four selected generations.

\section{Materials and Methods}

The current selection experiment was carried out at the poultry research farm at Faculty of Agriculture, Benha University, Egypt. Data of 3540 chicks that were obtained from 444 sires and 885 dams through five generations (base and four selected generations) were used in this study. Each breeding family consisted of one selected male and two selected females that were housed separately in a breeding cage $(25 \times 25 \times 25$ $\mathrm{cm}$ ) with a sloping floor for collecting the pedigreed eggs. These eggs were incubated to get the first selected generation $\left(G_{1}\right)$, then the selection was practised further on $G_{1}$ to obtain the consecutive second $\left(G_{2}\right)$, third $\left(G_{3}\right)$ and fourth $\left(G_{4}\right)$ selected generations based on their BLUP estimates for BW at four weeks old. In each generation, the pedigree eggs in each breeding pen were collected daily for ten days and then incubated. The structures of the data collected during the experiment are presented in Table 1.

Table 1 Numbers of sires, dams, females produced and chicks in a selection experiment with Japanese quail

\begin{tabular}{ccccc}
\hline Generation & Sires & Dams & Progeny (laying hens) & Chicks produced \\
\hline 0 & 125 & 249 & 260 & 688 \\
1 & 94 & 188 & 270 & 781 \\
2 & 82 & 164 & 264 & 684 \\
3 & 72 & 144 & 272 & 687 \\
4 & 71 & 140 & 266 & 700 \\
Total & 444 & 885 & 1332 & 3540 \\
\hline
\end{tabular}

In each generation, newly hatched chicks were wing banded. Chicks were raised on floor cages until 12 days old. After that, chicks were transferred to battery brooders. At five weeks old, all females were transferred to individual laying cages for accurate pedigree identification. All birds were fed a standard diet containing $240 \mathrm{~g} / \mathrm{kg}$ crude protein and $12.45 \mathrm{MJ} / \mathrm{kg}$ of metabolizable energy during the rearing period according to NRC (1994). Feed and drinking water were offered to birds ad libitum. The lighting duration was 24 hours during the first week old, reduced to 23 hours from the second to four weeks old. In the laying house, the lighting regimen was set at 16 hours light and 8 hours dark.

Bodyweights of 3540 chicks were obtained in grams at 0,2, 4 and 6 weeks old and presented as BW0, BW2, BW4, BW6, respectively. Bodyweight gain was calculated during the intervals from 0 to 2,2 to 4 , 4 to 6 , and 0 to 6 weeks old and presented as BWG0-2, BWG2-4, BWG4-6, and BWG0-6, respectively. Variance-covariance components were estimated by REML using the computer package VCE6 (Groeneveld et al., 2010). Multi-trait animal model (in matrix notation) was used to analyse growth traits using the following equation:

$$
y=X \beta+Z a+e
$$

Where: $y=n x 1$ vector of observations with $n=$ number of records,

$X=$ a $n x p$ incidence matrix which relates the data to a fixed effect of generation with five levels, 
$\beta=\mathrm{a} p \times 1$ vector of the fixed effects of generation,

$Z=$ an incidence matrix relating the data to additive genetic effects of the birds which are denoted by

$a$, and

$e=$ vector of random residual effects.

Variance components for growth traits were computed using the package of VCE6. Heritability estimates $\left(h_{a}^{2}\right)$ were calculated from the results as:

$$
h_{a}^{2}=\frac{\sigma_{a}^{2}}{\sigma_{a}^{2}+\sigma_{e}^{2}}
$$

Where: $\sigma_{a}^{2}$ and $\sigma_{e}^{2}$ are estimates of the variances due to direct additive genetic effects and random error, respectively. The genetic $\left(r_{g}\right)$ and phenotypic $\left(r_{p}\right)$ correlations among growth traits were also estimated. Estimated covariances were obtained by solving the corresponding mixed model equations for bivariate models.

The best linear unbiased predictors of $a$ for the birds with and without records were estimated using the PEST program (Groeneveld et al., 2010). Genetic trend was measured by regression of the $a$ values on generation number.

Estimates of correlated response in trait $y$ to selection on trait $x$ were calculated following Falconer and Mackay (1996):

$$
C R_{y}=i h_{x} h_{y} r_{g} \sigma_{p y}
$$

Where: $C R_{y}=$ the correlated response in trait $\mathrm{y}$,

$i=$ the selection intensity for trait $\mathrm{x}$,

$h_{x}$ and $h_{y}=$ square roots of heritability for traits $\mathrm{x}$ and $\mathrm{y}$, respectively,

$r_{g}=$ the genetic correlation of traits $\mathrm{x}$ and $\mathrm{y}$, and

$\sigma_{p y}=$ the phenotypic standard deviation of trait $\mathrm{y}$.

\section{Results and Discussion}

The actual means of BW were 9.5, 69.5, 152.2 and $241.4 \mathrm{~g}$ for chicks at $0,2,4$ and 6 weeks old, respectively. These findings agree with the reported live BW of Japanese quail at various ages in previous studies (Sezer et al., 2006; Varkoohi et al., 2011; Silva et al., 2013; Barbieri et al., 2015). The means of BWG in Japanese quail were 4.3,5.9, 6.4, and $5.5 \mathrm{~g}$ during the intervals from 0 to 2,2 to 4,4 to 6 , and 0 to 6 weeks old, respectively. Coefficients of variation (CV\%) ranged from $9.0 \%$ to $11.0 \%$ for $\mathrm{BW}$ and from $7 \%$ to $14 \%$ for BWG. Actual means, their standard deviations (SD) and percentages of variation (CV\%) for BW0, BW2, BW4 and BW6 and BWG0-2, BWG2-4, and BWG4-6 and BWG0-6 weeks in Japanese quail are reported in Table 2.

Table 2 Descriptive statistics of bodyweight and bodyweight gain for a selected population of Japanese quail

\begin{tabular}{lcrcr}
\hline Traits & Number of records & Mean & Standard deviation & CV,\% \\
\hline Weight at hatching & 3539 & 9.45 & 1.08 & 11 \\
Weight at 2 weeks & 3488 & 69.51 & 7.95 & 11 \\
Weight at 4 weeks & 3457 & 152.20 & 15.78 & 10 \\
Weight at 6 weeks & 3440 & 241.40 & 16.84 & 9 \\
Gain hatching to 2 weeks & 3488 & 4.29 & 0.54 & 13 \\
Gain from 2 to 4 weeks & 3457 & 5.91 & 0.83 & 14 \\
Gain from 4 to 6 weeks & 3440 & 6.37 & 0.77 & 72 \\
Gain hatching to 6 weeks & 3440 & 5.52 & 0.39 & 7 \\
\hline
\end{tabular}

These current findings agree with those previous studies, which showed that CV\% for BW ranged from 10.0 to 24.0 at various ages of Japanese quail (Narinc et al., 2010; Varkoohi et al., 2011; Barbieri et al., 
2015). Moreover, Özsoy and Aktan (2011) reported higher estimates of CV\% for BW2 (20.7\%) and BW4 $(16.5 \%)$ in Japanese quail.

In this study, heritability estimates of BW were decreasing with the advancement of age of Japanese quail. Estimated $h^{2}$ for BWO (0.42) was approximately twofold the $h^{2}$ of BW6 weeks (0.22). The current results agreed with those of previous studies (Shokoohmand et al., 2007; Silva et al., 2013; Ebrahimi et al., 2018; Mohammadi-Tighsiah et al., 2018). These findings could encourage the breeders to practise genetic selection at an early age in Japanese quail. In contrast, Saatci et al. (2003), Nasiri Foomani et al. (2014), and Karami et al. (2017) found that heritability values for BW of Japanese quail tended to increase with age. The estimated heritabilities $\left(h^{2}\right)$ and genetic and phenotypic correlations of BW and BWG of Japanese quail are shown in Table 3.

Table 3 Estimates of heritability (on the diagonal), genetic correlation (above the diagonal) and phenotypic correlation (below the diagonal) and the associated standard errors for bodyweight and bodyweight gain of Japanese quail

\begin{tabular}{lcccc}
\hline & \multicolumn{4}{c}{ Bodyweight } \\
\cline { 2 - 5 } & Hatching & 2 weeks & 4 weeks & 6 weeks \\
\hline Hatching & $0.42 \pm 0.04$ & $0.31 \pm 0.07$ & $0.44 \pm 0.09$ & $0.36 \pm 0.12$ \\
2 weeks & $0.15 \pm 0.02$ & $0.24 \pm 0.04$ & $0.59 \pm 0.18$ & $0.45 \pm 0.16$ \\
4 weeks & $0.08 \pm 0.01$ & $0.46 \pm 0.13$ & $0.36 \pm 0.04$ & $0.92 \pm 0.20$ \\
6 weeks & $0.05 \pm 0.01$ & $0.28 \pm 0.07$ & $0.65 \pm 0.19$ & $0.22 \pm 0.04$ \\
\cline { 2 - 5 } & \multicolumn{4}{c}{ Bodyweight gain } \\
\cline { 2 - 5 } & Hatching to 2 weeks & 2 to 4 weeks & 4 to 6 weeks & Hatching to 6 weeks \\
\hline Hatching to 2 weeks & $0.19 \pm 0.02$ & $0.12 \pm 0.03$ & $0.33 \pm 0.07$ & $0.53 \pm 0.05$ \\
2 to 4 weeks & $0.18 \pm 0.04$ & $0.22 \pm 0.02$ & $0.28 \pm 0.04$ & $.072 \pm 0.15$ \\
4 to 6 weeks & $0.17 \pm 0.04$ & $0.31 \pm 0.07$ & $0.18 \pm 0.02$ & $0.42 \pm 0.09$ \\
Hatching to 6 weeks & $0.27 \pm 0.03$ & $0.60 \pm 0.11$ & $0.48 \pm 0.05$ & $0.23 \pm 0.02$ \\
\hline
\end{tabular}

Genetic and phenotypic correlations for BW at various ages $(0,2,4$, and 6 weeks) were positive and in the ranges of 0.31 to 0.92 and 0.05 to 0.65 , respectively. For BW, estimates of genetic correlations between ages were higher than the corresponding phenotypic correlations. The highest value for genetic correlation was estimated between BW4 and BW6 (0.92) and the lowest was between BW0 and BW2 (0.31). Except for BW0 correlations with BW in various weeks, genetic correlations tended to increase with age. In addition, the correlation between consecutive closet BWs was higher than earlier. Genetic and phenotypic correlations were positive among BW at various ages, indicating that BW can be further improved with providing good management and climate conditions.

In agreement with the current findings, Silva et al. (2013) reported that genetic and phenotypic correlations between weekly BW of Japanese quail were 0.35 to 0.96 and 0.17 to 0.80 , respectively. In contrast, Karami et al. (2017) revealed a higher estimated genetic correlation of $0.85,0.90$ and 0.91 between BW0 with BW7, BW14 and BW21, respectively, in Japanese quail through a random regression model.

Estimated $h^{2}$ for BWG at different ages tended to be low, varying from 0.18 (BWG 4-6) to 0.23 (BWG 0-6). Estimates of genetic and phenotypic correlations for BWG at different ages $(0-2,2-4,4-6,0-6)$ were in the ranges of 0.12 to 0.72 and 0.17 to 0.60 , respectively. The highest genetic correlation was estimated between BWG2-4 and BWG0-6 (0.72) and the lowest was 0.12 for earlier ages (between BWG0-2 and BWG2-4). Caetano et al., (2017) reported that the estimate of $h^{2}$ for BWG0-3 weeks in a meat-type quail population was 0.15 . Also, in the study of Mohammadi-Tighsiah et al. (2018) the estimates of $h^{2}$ for BWG0-5 weeks and BWG15-20 weeks were 0.08 and 0.10 , respectively, which were lower than the present estimates in different periods.

Estimates of the selection for the four generations that were obtained by generalized least squares using VCE6 were superior $(P<0.05)$ for most BW and BWG to the base population (Tables 4 and 5 ). The contrasts among estimates of these generations were significant $(P<0.05)$. The fourth generation showed superiority in BW and BWG compared with the average of the first, second and third generations. 
Table 4 Generalized least-square estimates for bodyweights $(\mathrm{g})$ in different generations and contrasts of the generation means illustrating pattern of selection response in Japanese quail

\begin{tabular}{|c|c|c|c|c|}
\hline \multirow{2}{*}{ Generation means } & \multicolumn{4}{|c|}{ Bodyweight } \\
\hline & Hatching & 2 weeks & 4 weeks & 6 weeks \\
\hline 0 & $8.81 \pm 0.03^{d}$ & $58.22 \pm 1.21^{\mathrm{e}}$ & $134.47 \pm 2.74^{\mathrm{e}}$ & $223.35 \pm 3.12^{\mathrm{e}}$ \\
\hline 1 & $9.37 \pm 0.03^{c}$ & $67.24 \pm 1.26^{d}$ & $150.77 \pm 2.51^{d}$ & $237.08 \pm 3.42^{d}$ \\
\hline 2 & $9.70 \pm 0.03^{\mathrm{ab}}$ & $72.58 \pm 1.21^{c}$ & $153.17 \pm 2.74^{c}$ & $243.97 \pm 3.12^{c}$ \\
\hline 3 & $9.63 \pm 0.03^{b}$ & $74.57 \pm 1.21^{b}$ & $159.42 \pm 2.74^{b}$ & $250.13 \pm 3.12^{b}$ \\
\hline 4 & $9.75 \pm 0.03^{a}$ & $75.16 \pm 1.21^{a}$ & $163.46 \pm 2.74^{a}$ & $253.13 \pm 3.12^{a}$ \\
\hline \multicolumn{5}{|l|}{ Generation contrasts } \\
\hline 0 vs 1 & $-0.56 \pm 0.01^{*}$ & $-9.02 \pm 0.97^{*}$ & $-16.30 \pm 1.52^{*}$ & $-13.73 \pm 1.11^{*}$ \\
\hline 0 vs 2 & $-0.89 \pm 0.01^{*}$ & $-14.36 \pm 1.03^{*}$ & $-18.70 \pm 1.58^{*}$ & $-20.62 \pm 1.23^{*}$ \\
\hline 0 vs 3 & $-0.82 \pm 0.02^{*}$ & $-16.35 \pm 0.99^{*}$ & $-24.95 \pm 1.21^{*}$ & $-26.78 \pm 2.85^{*}$ \\
\hline 0 vs 4 & $-0.94 \pm 0.04^{\star}$ & $-16.94 \pm 1.01^{*}$ & $-28.99 \pm 2.52^{*}$ & $-29.78 \pm 2.63^{*}$ \\
\hline 1 vs 2 & $-0.33 \pm 0.02^{*}$ & $-5.34 \pm 0.88^{*}$ & $-2.40 \pm 0.09^{*}$ & $-6.89 \pm 1.42^{*}$ \\
\hline 1 vs 3 & $-0.26 \pm 0.02^{*}$ & $-7.33 \pm 0.91^{*}$ & $-8.65 \pm 0.87^{\star}$ & $-13.05 \pm 2.14^{*}$ \\
\hline 1 vs 4 & $-0.38 \pm 0.01^{*}$ & $-7.92 \pm 0.91^{*}$ & $-12.69 \pm 1.11^{\star}$ & $-16.05 \pm 1.21^{*}$ \\
\hline 2 vs 3 & $0.07 \pm 0.01$ & $-1.99 \pm 0.98^{*}$ & $-6.25 \pm 0.58^{*}$ & $-6.16 \pm 1.52^{*}$ \\
\hline 2 vs 4 & $0.07 \pm 0.01$ & $-2.75 \pm 0.89^{*}$ & $-10.29 \pm 1.12^{*}$ & $-9.16 \pm 1.91^{*}$ \\
\hline 3 vs 4 & $-0.12 \pm 0.01^{*}$ & $-0.59 \pm 0.80^{*}$ & $-4.04 \pm 0.88^{*}$ & $-3.0 \pm 1.41^{*}$ \\
\hline
\end{tabular}

$\overline{\mathrm{a}, \mathrm{b}, \mathrm{c}, \mathrm{d}}$ Within a column, estimates with a common superscript do not differ at $P=0.05$

* Contrast is significantly different from 0 at $\alpha=0.05$

Table 5 Generalized least-square estimates for bodyweight gain $(\mathrm{g} / \mathrm{d})$ in different generations and contrasts of the generation means illustrating the pattern of selection response in Japanese quail

\begin{tabular}{lcccc}
\hline Generation means & Hatching to 2 weeks & Weeks 2 to 4 & Weeks 4 to 6 & Hatching to 6 weeks \\
\hline 0 & $3.52 \pm 0.10^{\mathrm{d}}$ & $5.44 \pm 0.19^{\mathrm{e}}$ & $6.34 \pm 0.24^{\mathrm{b}}$ & $5.10 \pm 0.17^{\mathrm{e}}$ \\
1 & $4.13 \pm 0.13^{\mathrm{c}}$ & $5.96 \pm 0.22^{\mathrm{c}}$ & $6.16 \pm 0.25^{\mathrm{c}}$ & $5.42 \pm 0.19^{\mathrm{d}}$ \\
2 & $4.49 \pm 0.11^{\mathrm{b}}$ & $5.75 \pm 0.21^{\mathrm{d}}$ & $6.48 \pm 0.24^{\mathrm{a}}$ & $5.57 \pm 0.17^{\mathrm{c}}$ \\
3 & $4.63 \pm 0.11^{\mathrm{a}}$ & $6.06 \pm 0.21^{\mathrm{b}}$ & $6.47 \pm 0.24^{\mathrm{a}}$ & $5.72 \pm 0.17^{\mathrm{b}}$ \\
4 & $4.67 \pm 0.11^{\mathrm{a}}$ & $6.36 \pm 0.21^{\mathrm{a}}$ & $6.40 \pm 0.24^{\mathrm{ab}}$ & $5.79 \pm 0.17^{\mathrm{a}}$ \\
Generation contrasts & & & \\
0 vs 1 & $-0.61 \pm 0.08^{*}$ & $-0.52 \pm 0.08^{*}$ & $0.18 \pm 0.07^{*}$ & $-0.32 \pm 0.07^{*}$ \\
0 vs 2 & $-0.97 \pm 0.08^{*}$ & $-0.31 \pm 0.09^{*}$ & $-0.14 \pm 0.08^{*}$ & $-0.47 \pm 0.09^{*}$ \\
0 vs 3 & $-1.11 \pm 0.08^{*}$ & $-0.62 \pm 0.08^{*}$ & $-0.13 \pm 0.07^{*}$ & $-0.62 \pm 1.01^{*}$ \\
0 vs 4 & $-1.15 \pm 0.10^{*}$ & $-0.92 \pm 0.09^{*}$ & $-0.06 \pm 0.09$ & $-0.69 \pm 1.01^{*}$ \\
1 vs 2 & $-0.36 \pm 0.07^{*}$ & $0.21 \pm 0.08^{*}$ & $-0.32 \pm 0.08^{*}$ & $-0.15 \pm 0.09^{*}$ \\
1 vs 3 & $-0.50 \pm 0.08^{*}$ & $-0.10 \pm 0.07^{*}$ & $-0.31 \pm 0.06^{*}$ & $-0.30 \pm 0.08^{*}$ \\
1 vs 4 & $-0.54 \pm 0.05^{*}$ & $-0.40 \pm 0.09^{*}$ & $-0.24 \pm 0.07^{*}$ & $-0.37 \pm 1.11^{*}$ \\
2 vs 3 & $-0.14 \pm 0.07^{*}$ & $-0.31 \pm 0.09^{*}$ & $0.10 \pm 0.07$ & $-0.15 \pm 0.09^{*}$ \\
2 vs 4 & $-0.18 \pm 0.08^{*}$ & $-0.61 \pm 0.07^{*}$ & $0.08 \pm 0.07$ & $-0.22 \pm 0.09^{*}$ \\
3 vs 4 & $-0.04 \pm 0.09$ & $-0.30 \pm 0.08^{*}$ & $0.07 \pm 0.08$ & $-0.07 \pm 0.09$
\end{tabular}

$\overline{\mathrm{a}, \mathrm{b}, \mathrm{c}, \mathrm{d}}$ Within a column, estimates with a common superscript do not differ at $P=0.05$

* Contrast is significantly different from 0 at $\alpha=0.05$ 
Khaldari et al. (2010) reported that the mean of BW at four weeks old in the S line and C line in the last generation (fourth generation) was 200.5 and $170.9 \mathrm{~g}$, respectively, a $17.3 \%$ cumulative genetic improvement, or 5.8\% improvement per generation. Magda et al. (2010) showed that the means of six weeks' BW was 172.2, 186.3, 202.9, and $214.7 \mathrm{~g}$ for the base, first, second and third generations.

The BLUP estimates for BW0, BW2, BW4, and BW6 increased gradually as the generation advanced until they reached $0.07,1.17,3.90$, and $6.60 \mathrm{~g}_{\text {in }} \mathrm{G}_{4}$, respectively (Figure $1 \mathrm{a}, \mathrm{b}, \mathrm{c}$, and d). A similar genetic trend for BWG was recorded where the BLUP estimates for BWG0-2, BWG2-4, BWG4-6, and BWG0-6 increased gradually as the generation advanced untilthey reached $0.05,0.22,0.25$, and $0.18 \mathrm{~g}$ in $\mathrm{G}_{4}$, respectively (Figure 1e, f, g, and h).

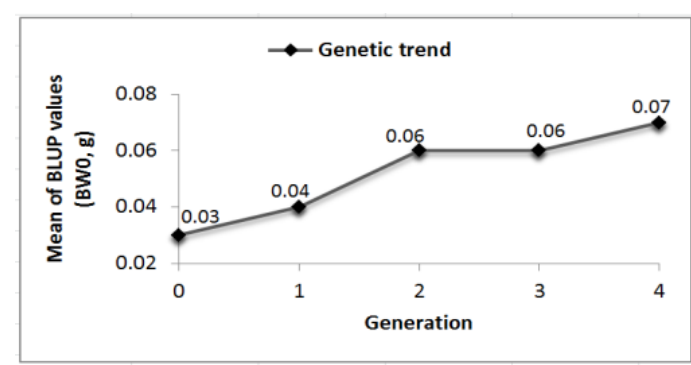

a

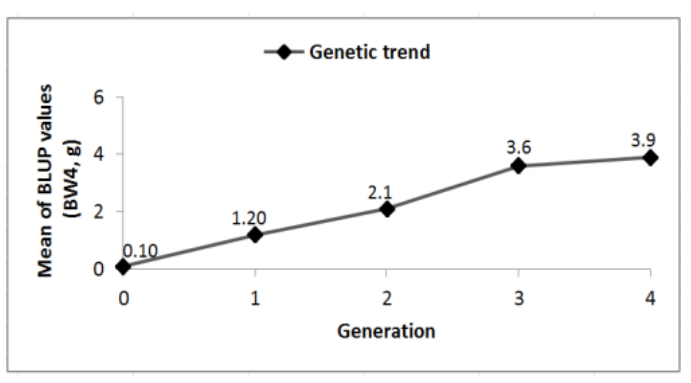

c

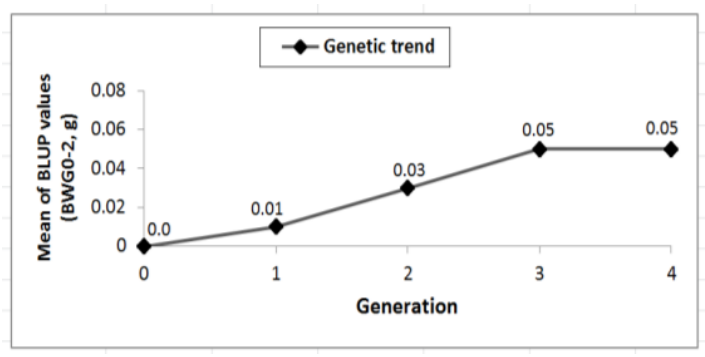

e

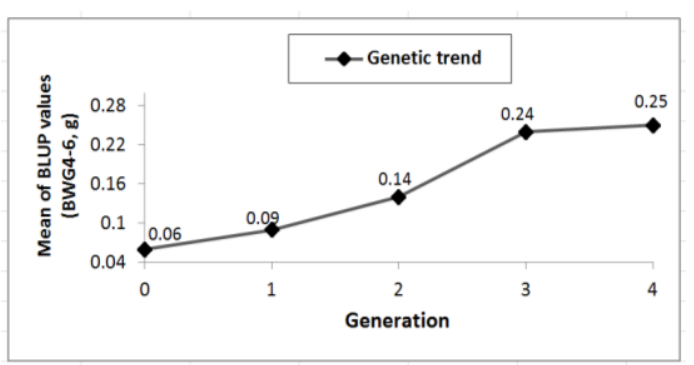

g

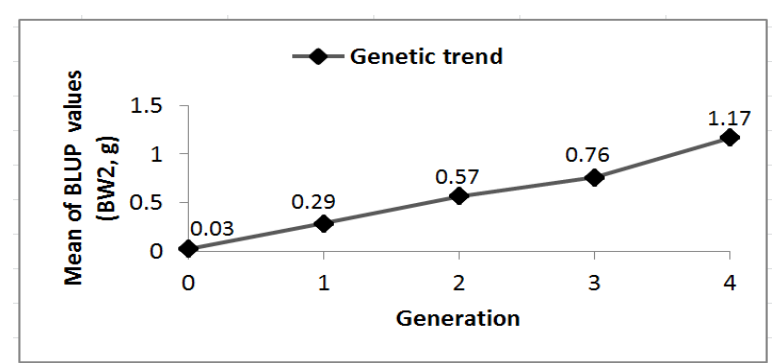

b

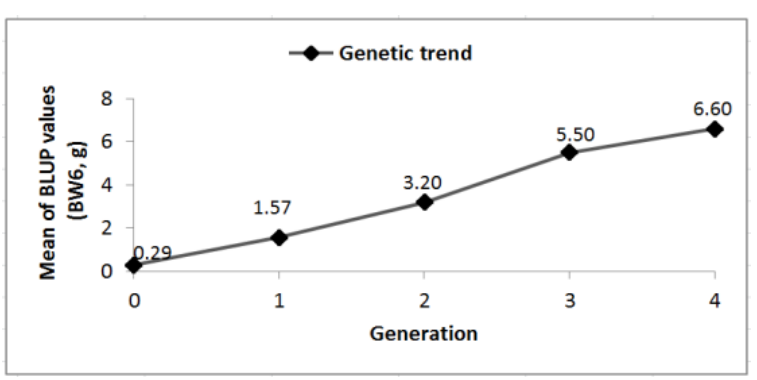

d

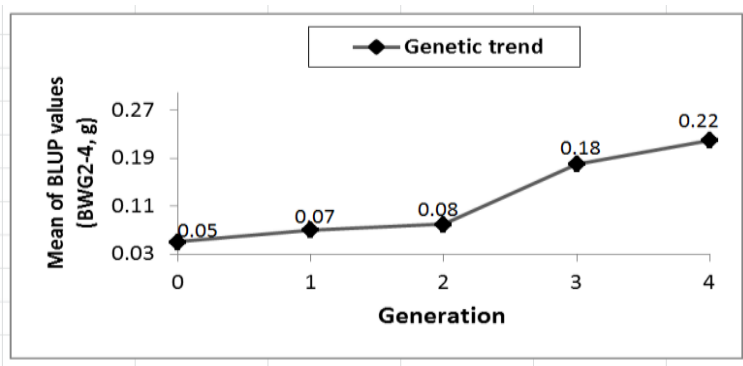

f

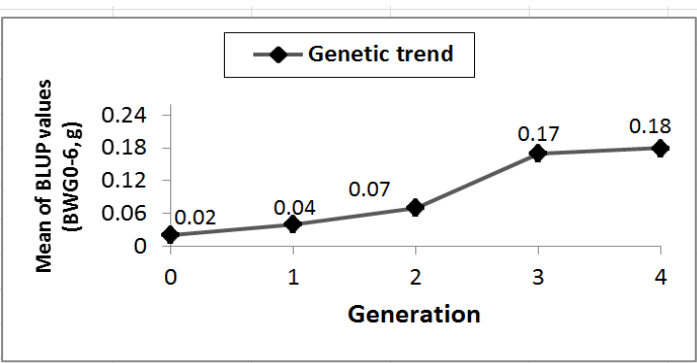

hours

Figure 1 Genetic trend for growth traits of bodyweight and bodyweight gain across the base and selected generations 
This increased genetic trend in the selected generations illustrated the efficiency of selection for BW at four weeks old. The estimation of genetic trend was necessary for the assessment of the breeding programmes. The current results agreed with those of Hussain et al. (2014), who observed a linear increasing trend of BW at three weeks old in selected populations as the generations progressed. On the other hand, Narinc et al. (2016) found that the mean of estimated BLUP values for BW in base population, first and second selected generations flocks were found to be $0.13,0.20$, and 0.34 , respectively.

The correlated response for unselected traits showed a positive correlation for increasing all BW at ages (Table 6). In all BW stages, the improve in BW decreased with the advance of generations. However, the cumulative correlated response of selection for BW0, BW2 and BW6 was increased dramatically by 0.83 , 10.88 and $25.45 \mathrm{~g}$, respectively. A similar trend was observed for BWG at different age intervals. These findings agree with the results of previous studies (Anthony et al., 1996; Ayatollahi Mehrgardi, 2013; Varkoohi, 2014; Hussen et al., 2016). These responses indicate that selection for BW at four weeks was associated with an increase in BW at different ages. The authors found that the correlated responses were due to the high genetic correlation between BW at four weeks old and other ages. This revealed that selection for higher BW at an early age would bring a concomitant improvement in BW at later ages as a correlated response to the selection.

Table 6 Correlated response to selection for four-week bodyweight in Japanese quail over four generations

\begin{tabular}{|c|c|c|c|c|c|}
\hline & \multicolumn{4}{|c|}{ Generation number } & \multirow{2}{*}{ Cumulative } \\
\hline & 1 & 2 & 3 & 4 & \\
\hline \multicolumn{6}{|l|}{ Bodyweight } \\
\hline Hatching & 0.44 & 0.27 & 0.04 & 0.08 & 0.83 \\
\hline 2 weeks & 5.42 & 3.54 & 1.41 & 0.51 & 10.88 \\
\hline 6 weeks & 12.32 & 4.93 & 5.35 & 2.85 & 25.45 \\
\hline \multicolumn{6}{|l|}{ Bodyweight gain } \\
\hline Hatching to 2 weeks & 0.54 & 0.31 & 0.11 & 0.06 & 1.06 \\
\hline Weeks 2 to 4 & 0.42 & 0.21 & 0.22 & 0.27 & 1.12 \\
\hline Weeks 4 to 6 & 0.14 & 0.29 & 0.08 & 0.05 & 0.56 \\
\hline Weeks 0 to 6 & 0.29 & 0.17 & 0.13 & 0.04 & 0.63 \\
\hline
\end{tabular}

\section{Conclusion}

Japanese quail respond quickly to selection for BW at four weeks old. The selected generations indicate that selection for BW at four weeks old was associated with an improvement in BW and BWG at other ages. Additionally, cumulative correlated responses of selection, genetic trends and BLUP estimates for BW and BWG increased gradually until the fourth generation. Hence, genetic improvement in growth performance could be achieved through practising BW selection at four weeks old and more improvement could be achieved through selection for more generations based on BLUP estimates.

\section{Acknowledgments}

The authors are grateful to Department of Animal Production, Faculty of Agriculture in Benha University, Egypt, for the facilities during the breeding experiment of the quail. This work was supported by the research project entitled Genetic Improvement for Japanese Quail Using Molecular Marker Tools from the Scientific Research Fund (SRF), Benha University, Egypt.

\section{Authors' Contributions}

MME and EAM designed the experiment and collected data. MME and SIR analysed the data and interpreted the results. MME wrote the draft manuscript and all authors cooperated in revising and finalizing the manuscript.

\section{Conflict of Interest Declaration}

The authors have declared that there are no competing interests.

\section{References}


Alkan, S., Karabağ, K., Galiç, A., Karslı, T. \& Balcıoğlu, M.S., 2010. Determination of bodyweight and some carcass traits in Japanese quails (Coturnix coturnix japonica) of different lines. Kafkas Univ. Vet. Fak. Derg. 16:277-280. DOI: 10.9775/kvfd.2009.687

Anthony, N.B., Nestor, K.E. \& Marks, H.L., 1996. Short-term selection for four-week bodyweight in Japanese quail. Poult. Sci. 75, 1192-1197.

Ayatollahi Mehrgardi, A., 2013. Divergent selection for four-week bodyweight in Japanese quail (Coturnix coturnix japonica): Response to selection and realized heritability. J. Livest. Sci. Technol. 1, 57-59.

Balcıoğlu, M.S., Kızılkaya, K., Yolcu, H.I. \& Karabağ, K., 2005. Analysis of growth characteristics in short-term divergently selected Japanese quail. S. Afr. J. Anim Sci. 35, 83-89.

Barbieri, A., Ono, R.K., Cursino, L.L., Farah, M.M., Pires, M.P. Bertipaglia, T.S., Pires, A.V., Cavani, L., Carreño, L.O.D. \& Fonseca, R., 2015. Genetic parameters for bodyweight in meat quail. Poult. Sci. 94, 169-171. https://doi.org/10.3382/ps/peu062

Baumgartner, J., 1994. Japanese quail production, breeding and genetics. Worlds Poult. Sci. J. 50, $227-235$.

Boni, I., Nurul, H. \& Noryati, I., 2010. Comparison of meat quality characteristics between young and spent quails. Int. Food Res. J. 17, 661-667.

Caetano, G.C., Mota, R.R., da Silva, D.A., de Oliveira, H.R., Viana, J.M.S., de Siqueira, O.H.G., Freitas, P.H.F. \& de Silva, F.F., 2017. Bayesian estimation of genetic parameters for individual feed conversion and bodyweight gain in meat quail. Livest. Sci. 200, 76-79. https, //doi.org/10.1016/j.livsci.2017.04.011

Caron, N., Minvielle, F., Desmarais, M. \& Poste, L.M., 1990. Mass selection for 45-day bodyweight in Japanese quail: selection response, carcass composition, cooking properties, and sensory characteristics. Poult. Sci. 69:10371045. http://dx.doi.org/10.3382/ps.0691037

Darden, J.R. \& Marks, H.L.1988. Divergent selection for growth in Japanese quail under split and complete nutritional environments. 1. Genetic and correlated responses to selection. Poult. Sci. 67, 519-529.

Durmus, I., Alkan, S., Narinc, D., Karabag, K. \& Karsli, T., 2017. Effects of mass selection on egg production on some reproductive traits in Japanese quail. Europ. Poult. Sci. 1, 81.

Ebrahimi, K., Dashab, G.R., Faraji-Arough, H. \& Rokouei, M., 2019. Estimation of additive and non-additive genetic variances of bodyweight in crossbreed populations of the Japanese quail. Poult. Sci. 98, 46-55. https://doi.org/10.3382/ps/pey357

Falconer, D.S. \& Mackay, F.C., 1996. Introduction to quantitative genetics. Fourth edition. Longman Group, Harlow, Essex, England. p.p.108-183.

Groeneveld, E., Kovac, M. \& Mielenz, N., 2010. VCE - user's guide and reference manual, version 6.0. Institute of Farm Animal Genetics, Neustadt, Germany.

Hussain, J., Akram, M., Sahota, A.W., Javed, K., Ahmad, H.A., Mehmood, S., Jatoi, A.S. \& Ahmad, S., 2014. Selection for higher three-week bodyweight in Japanese quail: 2. Estimation of genetic parameters. J. Anim. Plant. Sci. 24, 869-873.

Hussen, S.H., Abdulrahman Al-Khdri, A.M. \& Hassan, A.M., 2016. Response to selection for bodyweight in Japanese quail (Coturnix coturnix japonica). Iran. J. Appl. Anim. Sci. 453-459.

Karami, K., Zerehdaran, S., Tahmoorespur, M., Barzanooni, B. \& Lotfi, E., 2017. Genetic evaluation of weekly bodyweight in Japanese quail using random regression models. Br. Poult. Sci. 58, 13-18. https://doi.org/10.1080/00071668.2016.1236362

Khaldari, M., Pakdel, A., Mehrabani Yegane, H., Nejati Javaremi, A. \& Berg, P., 2010. Response to selection and genetic parameters of body and carcass weights in Japanese quail selected for 4-week bodyweight. Poult. Sci. 89, 18341841. https://doi.org/10.3382/ps.2010-00725

Magda, I., Abo Samaha, M., Sharaf, M. \& Hemeda, S.A., 2010. Phenotypic and genetic estimates of some productive and reproductive traits in Japanese quails. E Egypt. Poult. Sci. 30, 875-892.

Marks, H.L., 1993. Carcass composition, feed intake, and feed efficiency following long-term selection for four-week bodyweight in Japanese quail. Poult. Sci. 72:1005-1011. https://doi.org/10.3382/ps.0721005

Marks, H.L., 1996. Long-term selection for bodyweight in Japanese quail under different environments. Poult. Sci. 75 , 1198-1203. https://doi.org/10.3382/ps.0751198

Minvielle, F., Monvoisin, J.L., Costa, J. \& Maeda, Y., 2000. Long-term egg production and heterosis in quail lines after within-line or reciprocal recurrent selection for high early egg production. Br. Poult. Sci. 41, 150-157. https://doi.org/10.1080/713654914

Minvielle, F., 2004. The future of Japanese quail for research and production. Worlds. Poult. Sci. J. 60, 500-507. https://doi.org/10.1079/WPS200433

Mizutani, M., 2003. The Japanese quail. Laboratory Animal Research Station, Nippon Institute for Biological Science, Kobuchizawa, Yamanashi, Japan, 408-0041.

Mohammadi-Tighsiah, A., Maghsoudi, A., Bagherzadeh-Kasmani, F., Rokouei, M. \& Faraji-Arough, H., 2018. Bayesian analysis of genetic parameters for early growth traits and humoral immune responses in Japanese quail. Livest. Sci. 216, 197-202. https://doi.org/10.1016/j.livsci.2018.07.012

Narinc, D., Aksoy, T. \& Karaman, E., 2010. Genetic parameters of growth curve parameters and weekly bodyweights in Japanese quails (Coturnix coturnix japonica). J. Anim.Vet. Adv. 9, 501-507.

Narinç, D., Aksoy, T. \& Kaplan, S., 2016. Effects of multi-trait selection on phenotypic and genetic changes in Japanese quail (Coturnix coturnix japonica). J. Poult. Sci. 53, 103-110, DOI: 10.2141/jpsa.0150068

Nasiri Foomani, N., Zerehdaran, S., Ahani Azari, M. \& Lotfi, E., 2014. Genetic parameters for feed efficiency and bodyweight traits in Japanese quail. Br. Poult. Sci. 55, 298-304. https://doi.org/10.1080/00071668.2014.925088 
Nestor, K.E., Anderson, J.W. \& Patterson, R.A., 2000. Effects of selection for increased bodyweight, egg production, and shank width on developmental stability in turkeys. Poult. Sci. 79, 937-945. https://doi.org/10.1093/ps/79.7.937

Nestor, K.E., Bacon, W.L. \& Lambio, A.L., 1983. Divergent selection for egg production in Coturnix coturnix japonica. Poult. Sci. 62, 1548-1552. https://doi.org/10.3382/ps.0621548

NRC, 1994. Nutrient requirements of poultry. 9th revised edition. National Academic Press, Washington, DC, USA.

Özsoy, A.N. \& Aktan, S., 2011. Estimation of genetic parameters for body weight and egg weight traits in Japanese quails. Trends Anim. Vet. Sci. 2(1), 17-20.

Resende, R.O., Martins, E.N., Georg, P.C., Paiva, E., Conti, A.C.M., Santos, A.I., Sakaguti, E.S. \& Murakami, A.E., 2005. Variance components for bodyweight in Japanese quails (Coturnix japonica). Braz. J. Poult. Sci. 7, $23-25$. https://doi.org/10.1590/S1516-635X2005000100004

Saatci, M., Ap Dewi, I. \& Aksoy, A.R., 2003. Application of REML procedure to estimate the genetic parameters of weekly live weights in one to one sire and dam pedigree recorded Japanese quail. J. Anim. Breed. Genet. 120, 23-28. https://doi.org/10.1046/j.1439-0388.2003.00370.x

Saatci, M., Omed, H. \& Ap Dewi, I., 2006. Genetic parameters from univariate and bivariate analyses of egg and weight traits in Japanese quail. Poult. Sci. 85, 185-190. https://doi.org/10.1093/ps/85.2.185

Sezer, M., Berberoglu, E. \& Ulutas, Z., 2006. Genetic association between sexual maturity and weekly live-weights in laying-type Japanese quail. S. Afr. J. Anim. Sci. 36, 142-148. https://doi.org/10.4314/sajas.v36i2.3997

Shokoohmand, M., Kashan, N.E.J. \& Maybody, M. E., 2007. Estimation of heritability and genetic correlations of bodyweight in different age for three strains of Japanese quail. Int. J. Agric. Biol. 9, 945-947.

Silva, L.P., Ribeiro, J.C., Crispim, A.C., Silva, F.G., Bonafé, C.M., Silva, F.F. \&Torres, R.A., 2013. Genetic parameters of bodyweight and egg traits in meat-type quail. Livest. Sci. 153, 27-32. https://doi.org/10.1016/j.livsci.2013.01.014

Toelle, V.D., Havenstein, G.B., Nestor, K.E. \& Harvey, W.R., 1991. Genetic and phenotypic relationships in Japanese quail. 1. Bodyweight, carcass, and organ measurements. Poult. Sci. 70, 1679-1688. https://doi.org/10.3382/ps.0701679

Varkoohi, S. \& Kaviani, K., 2014. Genetic improvement for bodyweight of Japanese quail. Annu. Res. Rev. Biol. $347-353$. https://doi.org/10.9734/ARRB/2014/5281

Varkoohi, S., Pakdel, A., Moradi Shahr Babak, M., Nejati Javaremi, A., Kause, A. \& Zaghari, M., 2011. Genetic parameters for feed utilization traits in Japanese quail. Poult. Sci. 90, 42-47. DOI: 10.3382/ps.2010-01072 